\title{
Tunable high-power narrow-linewidth semiconductor laser based on an external-cavity tapered amplifier at $670 \mathrm{~nm}$
}

Chi, Mingjun; Jensen, Ole Bjarlin; Erbert, G.; Sumpf, B.; Petersen, Paul Michael

Published in:

Conference on Lasers \& Electro Optics \& The Pacific Rim Conference on Lasers and Electro-Optics

Link to article, DOI:

10.1109/CLEOPR.2009.5292354

Publication date:

2009

Document Version

Publisher's PDF, also known as Version of record

Link back to DTU Orbit

Citation (APA):

Chi, M., Jensen, O. B., Erbert, G., Sumpf, B., \& Petersen, P. M. (2009). Tunable high-power narrow-linewidth semiconductor laser based on an external-cavity tapered amplifier at $670 \mathrm{~nm}$. In Conference on Lasers \& Electro Optics \& The Pacific Rim Conference on Lasers and Electro-Optics: CLEO/PACIFIC RIM '09. (pp. 1-2). IEEE. https://doi.org/10.1109/CLEOPR.2009.5292354

\section{General rights}

Copyright and moral rights for the publications made accessible in the public portal are retained by the authors and/or other copyright owners and it is a condition of accessing publications that users recognise and abide by the legal requirements associated with these rights.

- Users may download and print one copy of any publication from the public portal for the purpose of private study or research.

- You may not further distribute the material or use it for any profit-making activity or commercial gain

- You may freely distribute the URL identifying the publication in the public portal 


\title{
Tunable High-Power Narrow-Linewidth Semiconductor Laser Based on an External-Cavity Tapered Amplifier at 670 nm
}

\author{
Mingjun $\mathrm{Chi}^{1}$, Ole B. Jensen ${ }^{1}$, G. Erbert ${ }^{2}$, B. Sumpf ${ }^{2}$, P. M. Petersen ${ }^{1}$ \\ ${ }^{1}$ Department of Photonics Engineer, Technical University of Denmark, P.O. Box 49, DK-4000 Roskilde, Denmark \\ ${ }^{2}$ Ferdinand-Braun-Institut für Höchstfrequenztechnik, Gustav-Kirchhoff-Str. 4, 12489 Berlin, Germany \\ E-mail:mingjun.chi@risoe.dk
}

\begin{abstract}
A narrow-linewidth laser system based on a tapered semiconductor optical amplifier in external cavity is demonstrated. $800 \mathrm{~mW}$ output power is obtained, and the laser system is tunable from 655 to $679 \mathrm{~nm}$.
\end{abstract}

Keywords: Semiconductor tapered amplifier, external-cavity

\section{INTRODUCTION}

Diffraction-limited high-power narrow-linewidth red diode lasers are attractive in a number of key applications, such as high-resolution spectroscopy, laser cooling, and second harmonic generation toward UV light. High-power, diffraction-limited diode lasers can be realized by the introduction of the technology of lasers with a tapered gain-region [1]. More than $1 \mathrm{~W}$ output power around 670 $\mathrm{nm}$ from a Fabry-Perot tapered diode laser was obtained with a beam propagation factor of 1.7 , and the spectral width was smaller than $0.2 \mathrm{~nm} \mathrm{[2].} \mathrm{Around} 670 \mathrm{~nm}$, narrow-linewidth diffraction-limited output was also achieved from master oscillator power amplifier system [3, 4]. In pulse operation mode, $5 \mathrm{~W}$ peak power was obtained from a micro-external cavity tapered laser with the beam propagation factor of 10 , and the spectral width below 150 pm [5]. External cavity based on a bulk diffraction grating in a Littrow configuration is a useful technique to get a tunable narrow-linewidth, high-power, and diffraction-limited tapered diode laser system [6]. Here, we present the experimental results of a tapered diode laser system based on a Littrow external cavity. $800 \mathrm{~mW}$ output power is obtained. The laser system is tunable from 655 to $679 \mathrm{~nm}$ with linewidth less than $100 \mathrm{pm}$.

\section{EXPERIMENTAL SETUP}

The laser structure of the $670 \mathrm{~nm}$ tapered amplifier was grown using metal organic vapor phase epitaxy. As active layer a $5 \mathrm{~nm}$ thick compressively strained single InGaP quantum well was used, which was embedded in AlGaInP waveguide layers. On the $n$-side the cladding layer was made of AlInP whereas the p-side cladding consists of AlGaAs. The processed tapered gain media had a total length of $2 \mathrm{~mm}$, a $0.75 \mathrm{~mm}$ long index guided ridge- waveguide section and a $1.25 \mathrm{~mm}$ long flared section. The tapered angle is $4^{\circ}$, and the output aperture is $95 \mu \mathrm{m}$. The rare facet was anti-reflection coated with a reflectivity of $5 \times 10^{-4}$, whereas the front facet had a reflectivity of $1 \%$. The external cavity configuration employed is depicted in Fig. 1. An aspherical lens of 3.1-mm focal length with a N.A. of 0.68 is used to collimate the beam from the back facet in both fast and slow axes. The bulk grating is ruled with 1200 grooves $/ \mathrm{mm}$ and has a blazed wavelength of $750 \mathrm{~nm}$. The grating is mounted in the Littrow configuration and oriented with the lines in the grating parallel to the active region of the amplifier. The laser cavity is formed between the diffraction grating and the front facet of the tapered amplifier. Another aspherical lens of 3.1-mm focal length with a N.A. of 0.68 is used to collimate the beam from the output facet in the fast axis. Together with a cylindrical lens of $65-\mathrm{mm}$ focal length, these two lenses collimate the output beam in the slow axis and compensate the astigmatism simultaneously. All the lenses are antireflection coated for the red wavelength. A beam splitter behind the cylindrical lens is used to reflect part of the output beam of the tapered diode laser system as the diagnostic beam, the beam quality factor $M^{2}$ is measured in this beam.

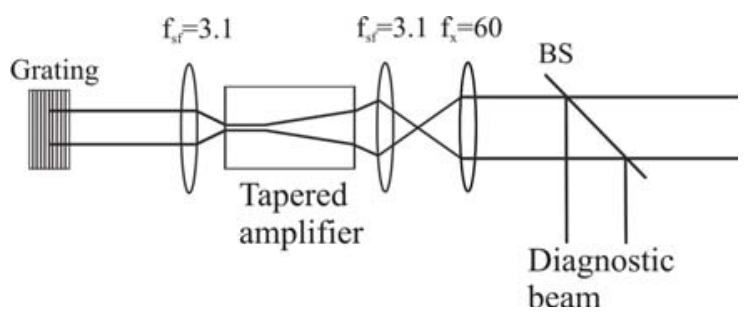

Fig. 1. Experimental set-up of the tapered diode laser system using a bulk diffraction grating external cavity. BS: beam splitter, (the units are in $\mathrm{mm}$ ).

\section{EXPERIMENTAL RESULTS}

The laser is TE-polarized, i.e., linearly polarized along the slow axis. The temperature of the amplifier is controlled with a Peltier element and it is operated at $15^{\circ} \mathrm{C}$ in the experiment. The emission wavelength of the laser system is tuned by rotating the diffraction grating. The output power is measured behind the aspherical lens. The power/current characteristics for the laser system is shown in Fig. 2. The threshold current is around $0.3 \mathrm{~A}$, and the slope efficiency is around $0.62 \mathrm{~W} / \mathrm{A}$. More than $800 \mathrm{~mW}$ output power is obtained with the operating current of $1.7 \mathrm{~A}$. The output power at different wavelength is shown in Fig. 3 at an operating current of $1.7 \mathrm{~A}$. The laser system is tuned over a $24 \mathrm{~nm}$ range certered at $667 \mathrm{~nm}$. As high as $810 \mathrm{~mW}$ output 
power is obtained at the wavelength of $668.36 \mathrm{~nm}$, and an output power above $400 \mathrm{~mW}$ is achieved from 656 to 678 nm.

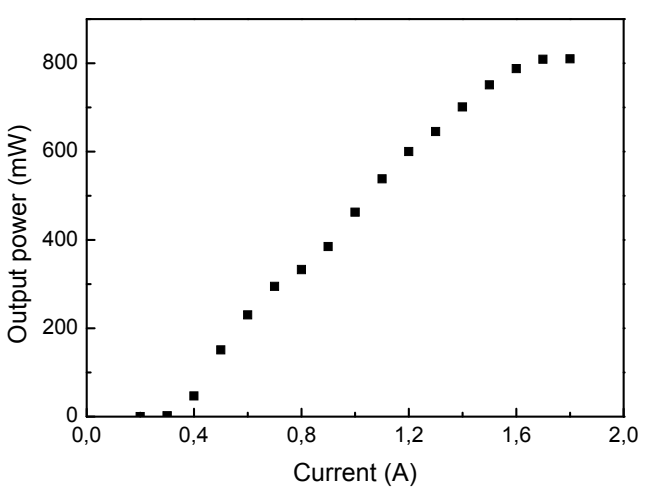

Fig. 2. The power/current characteristics for the tapered diode laser system.

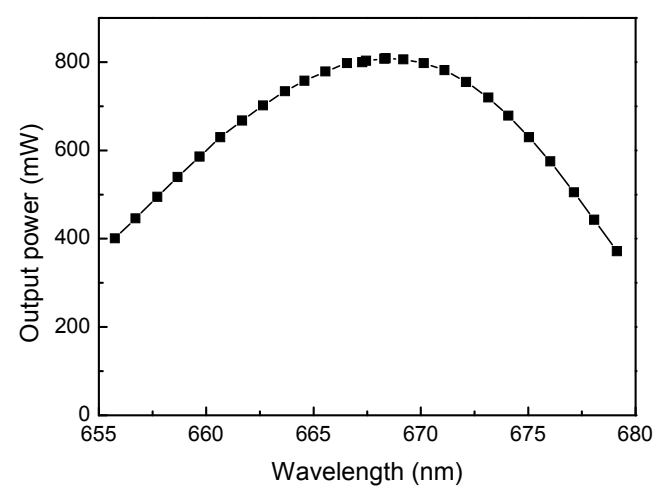

Fig. 3. Tuning curve of the tapered diode laser system at an operating current of $1.7 \mathrm{~A}$.

The beam quality of the output beam along the slow axis is estimated by measuring the beam quality factor $M^{2}$ for the external cavity laser system. A spherical lens with a $100-\mathrm{mm}$ focal length is used to focus the diagnostic beam. Then the beam width, $W\left(1 / \mathrm{e}^{2}\right)$, is measured at various recorded positions along the optical axis - on both sides of the beam waist. The value of $M^{2}$ is obtained by fitting the measured data with a hyperbola. Fig. 4 shows the measured beam widths and the fitted curves with the output power of $295 \mathrm{~mW}$ and $606 \mathrm{~mW}$. The estimated $M^{2}$ values are $1.35 \pm$ 0.07 with $295 \mathrm{~mW}$ output power and $3.39 \pm 0.07$ with 606 $\mathrm{mW}$ output power. So the beam quality is diffraction-limited when the output power is less than $300 \mathrm{~mW}$. The beam quality deteriorates at high output power, and the reason may be the heating effect and/or higher current density [5].

The optical spectrum characteristic of the output beam from the tapered diode laser system is measured using a spectrum analyzer (Advantest Corp. Q8347). A typical result measured at $665.83 \mathrm{~nm}$ with the output power of 210 $\mathrm{mW}$ is shown in Fig. 5. The linewidth (FWHM) is 0.007 $\mathrm{nm}$, and the amplified spontaneous emission intensity is around $20 \mathrm{~dB}$ suppressed. We find the linewidth is below $0.01 \mathrm{~nm}$ when the output power is less than $300 \mathrm{~mW}$, and the linewidth is below $0.1 \mathrm{~nm}$ with the output power of 810 $\mathrm{mW}$.

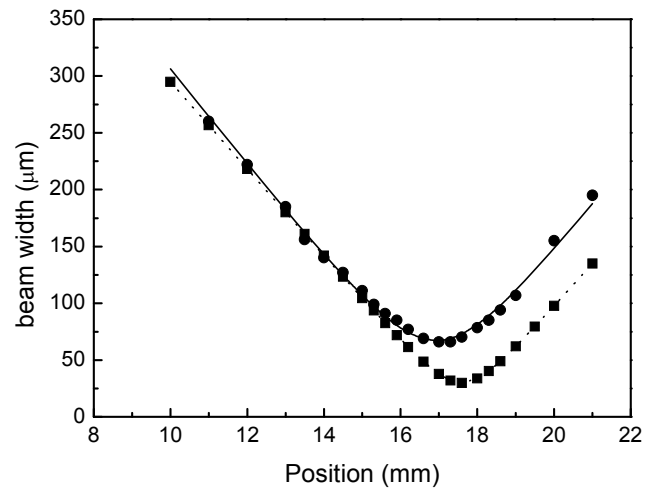

Fig. 4. Beam width of the output beam from the tapered diode laser system for the slow axis with the output power of $295 \mathrm{~mW}$ (squares and dot line), and $606 \mathrm{~mW}$ (circles and solid line). The curves represent byperbola fits to the measured data.

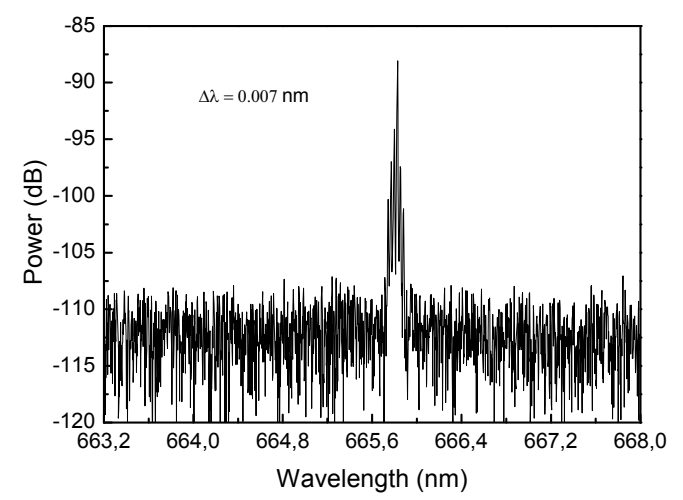

Fig. 5. The optical spectrum of the output beam from the tapered diode laser system with the output power of $210 \mathrm{~mW}$.

\section{CONCLUSION}

A diode laser system based on a tapered semiconductor optical amplifier in external cavity is demonstrated. More than $800 \mathrm{~mW}$ output power is obtained, and the laser system is tunable from 655 to $679 \mathrm{~nm}$. The linewidth is less than 0.1 $\mathrm{nm}$.

[1] H. Wenzel, B. Sumpf. and G. Erbert, "High-brightness diode laser," C. R. Physique, vol. 4, pp. 649-661, July-August 2003.

[2] B. Sumpf, G. Erbert, J. Fricke, P. Froese et al., " $670 \mathrm{~nm}$ tapered lasers and amplifiers with output powers $\mathrm{P} \geq 1 \mathrm{~W}$ and nearly diffraction limited beam quality," Proc. SPIE, vol. 6485, pp. 648517 (8 pages), January 2007.

[3] G. Ferrari, M. Mewes, F. Schreck, and C. Salomon, "High-power multiple-frequency narrow-linewidth laser scource based on a semiconductor tapered amplifier," Opt. Lett., vol. 24, pp. 151-153, February 1999.

[4] R. Häring, B. Sumpf, G. Erbert, G. Tränkle, F. Lison, and W. G. Kaenders, "670 nm semiconductor lasers for Lithium spectroscopy with 1 W, " Proc. SPIE, vol. 6485, pp. 648516 (6 pages), January 2007.

[5] T. Q. Tien, M. Maiwald, B. Sumpf, G. Erbert, and G. Tränkle, "Microexternal cavity tapered lasers at $670 \mathrm{~nm}$ with $5 \mathrm{~W}$ peak power and nearly diffraction-limited beam quality," Opt. Lett., vol. 33, pp. 2692-2694, November 2008.

[6] M. Chi, O. B. Jensen, J. Holm, C. Pedersen, P. E. Andersen et al., "Tunable high-power narrow-linewidth semiconductor laser based on an external-cavity tapered amplifier," Opt. Express, vol. 13, pp. 10589-10596, December 2005. 